\title{
Dr Michael F. Borgerding, Recipient of the 2015 Tobacco Science Research Conference Lifetime Achievement Award
}

\author{
Laudatio to the award given by
}

Joy Bodnar, Master Scientist, RAI Services Company

401 N Main Street, Winston-Salem, NC 27101, USA

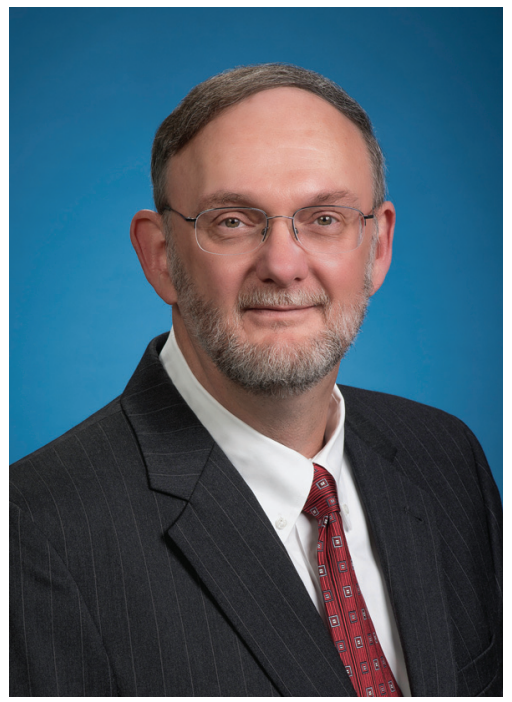

It is with great pleasure that I introduce to you Dr Michael Francis Borgerding as the 2015 recipient of the Lifetime Achievement Award for tobacco science. Dr Borgerding has 35 years' experience in the tobacco industry.

A little known fact about Mike, he was born in Audubon, Iowa. His dad worked as an engineer for the government in (cartography) map making and so they moved around some. Mike was raised in Fairfax, VA. He obtained his BS in Biochemistry at VA Tech. He obtained his MS in chemistry at VA Tech in 1980 working for Dr Harold McNair and his $\mathrm{PhD}$ in chemistry from Wake Forest University in 1988 working for Dr Willie Hinze.

He started with RJ Reynolds Tobacco Co in 1980 as a junior chemist developing and applying analytical methods using gas and liquid chromatography. He worked his way up in title and skill levels over the years from an associate

research chemist in 1982 investigating tobacco and tobacco smoke, to a Research Chemist in New Technology Department and his first supervisory job in 1984, to a Sr. Research Chemist who directed efforts to support new products and product development in 1987.

In the 1980s Dr Borgerding's focus was on developing improved methods of determining carbonyls in cigarette smoke, the analysis of essential oils from flue-cured tobacco and separating and analyzing several compounds (such as phenols, pyridine, quinoline, etc.) in mainstream cigarette smoke by multi-dimensional mass spectrometry. In the late 1980s and early 1990s, Dr Borgerding became heavily involved in the chemical and biological studies of a cigarette that heated rather than burned tobacco and the characterization of mainstream smoke produced by such cigarettes compared to burn-down cigarettes. During this time he alerted the tobacco community to the limitations of the FTC method for characterizing this type of cigarette. In the mid-1990s he became involved in exploring the effect of alternative smoking regimens on cigarette performance and in the late 1990s he engaged the Massachusetts Department of Public Health and others in the tobacco industry when the Massachusetts smoking regimen and cigarette reporting requirements were mandated. (Texas later adopted reporting requirements similar to Massachusetts). Dr Borgerding was one of the principal investigators of the Massachusetts Benchmark Study which in 1999 provided a body of evidence that functional relationships could be used to estimate cigarette yields at the Massachusetts smoking regimen from yields obtained at the FTC smoking regimen. This allowed the tobacco industry to meet the state reporting requirements of Massachusetts and Texas in the timeframe required. This benchmarking study has since been cited in many other attempts to utilize functional relationships to determine tobacco smoke constituent yields. 
It was in 1997 that Mike became an adjunct Professor of Chemistry at VT. There in collaboration with Drs Harold McNair and Larry Taylor and their post doctoral research students, they investigated the precursor/fate relationships of complex chemical systems in cigarette smoke using gas chromatography with atomic emission detection. During this time, Mike mentored post-doctoral fellows in research related to the fate of principal tobacco blend components upon smoking of a cigarette, development of analytical methodology to determine polycyclic aromatic hydrocarbon metabolites and potential relationships between cigarette mainstream smoke constituents and observations in vitro biological activity.

It was in 1997 that Dr Borgerding also received the Phillip Morris Award for Distinguished Achievement in Tobacco Science.

In the early 2000s, Dr Borgerding was involved in various toxicological studies of cigarette design changes. As the tobacco industry became more concerned with reporting regulations and proposed alternative smoking regimens, Dr Borgerding and Dr Hubert Klus in 2005 wrote a review article on the complexity of analyzing cigarette smoke that explores the strategy for establishing an alternative smoke generation method and the effects on analytical accuracy and precision. They also discussed the effect of alternative smoking regime on the yields of Hoffmann analytes and on the World Health Organization recommendations at that time. Dr Borgerding was one of only two scientists from the United States to participate in an international expert working group, ISO TC126 Working Group 9, which was charged with identifying a smoking regime that is more representative of the ways in which people smoke; a first step in establishing a new, international standard for testing cigarettes.

During the mid-2000s, Dr Borgerding also began working with Dr Larry Taylor and one of his graduate students at VA Tech studying the effect of alternate puffing parameters and vent filter blocking on nicotine fate in a burning cigarette.

Over the years Mike continued to advance at RJR in title and responsibilities and became Principal Scientist and then Senior Principal Scientist and expanded his responsibilities into the area of regulatory affairs and product chemistry. In 2006 Mike received a bronze medal from CORESTA for his contributions to tobacco science. In 2007 Mike took on new duties as head of RJR's clinical study group and led efforts to study the interaction of tobacco users with tobacco products, including behavioral measures, quality of life measures, biomarkers of exposure and biomarkers of potential harm and he led clinical studies to evaluate new and existing tobacco products. In 2008 Mike became a Senior Director in Product Integrity leading the Clinical Studies Division.

In 2008 and 2009 Dr Borgerding became involved in risk assessment modeling of mainstream smoke constituent yields and had work presented at the CORESTA meeting and the Society of Toxicology meeting with C. Wilson and Z. Naufal. Continuing in his interest in exploring human smoking exposure, in 2010, Dr Borgerding and Kelley St. Charles wrote an article exploring the difference between machine and human smoking as it relates to estimated tar and nicotine exposure.
In 2010, Dr Borgerding continued working with Dr Larry Taylor at VA Tech in exploring the generation of acrolein and acetone from glycerin when cigarettes were smoked under alternative smoking regimens. Also in that year, Dr Borgerding led a multi-part cardiovascular biomarker study which explored tobacco-related biomarkers of exposure and effect and this resulted in a series of presentations at CORESTA Congress in Edinburgh.

Continuing in his interest in cardiovascular disease biomarkers Dr Borgerding worked with Kristin Marano and others to present a comparison of the National Health and Nutritional Examination Survey and a Single Site CrossSectional Study in 2011 at the Society of Toxicology annual meeting. Dr Borgerding continued working with Kristin and others to publish what is known of arsenic and cadmium exposure and tobacco consumption from an epidemiology, biomarker and risk assessment viewpoint in 2012.

In 2012 Dr Borgerding also published a survey of smokeless products found in the U.S. marketplace and their tobacco constituent yields. This was one of the first smokeless tobacco product surveys of the U.S. marketplace. That same year he and Betsy Bombick led an investigation of the cytotoxicity of different tobacco preparations and Dr Borgerding continued his interest in quantitative risk assessment by co-authoring a symposium presentation with Kristin Marano at the $66^{\text {th }}$ TSRC in Concord, NC.

In 2013, Dr Borgerding continued his work with Dr Larry Taylor and others in exploring trace analysis of mutagenic heterocyclic aromatic amines in cigarette smoke condensate and its base fractions. In 2014 Dr Borgerding was publishing in the area of comparing consumption patterns and biomarkers of exposure for cigarette smokers who had switched to dissolvable tobacco or to snus. In $2015 \mathrm{Dr}$ Borgerding has had six publications in the area of biomarker magnitude reduction in a clinical confinement study, cardiovascular disease biomarkers among tobacco consumers, biomarkers of exposure and biomarkers of biological effect, cardiovascular disease biomarkers evaluation and comparison with the US National Health and Nutrition Examination Survey and changes in biomarkers of exposure and subjective effects when smokers switch to dual use of cigarettes and either snus or dissolvable tobacco products. Results of such studies provide a means of placing tobacco products on a risk continuum.

Currently, Mike has transitioned in January of this year to RAI Services Company as a Senior Director in Regulatory Oversight.

It is with great honor tonight that I present the 2015 Lifetime Achievement Award on behalf of the $69^{\text {th }}$ TSRC policy committee to Dr Michael Borgerding.

\author{
Joy Bodnar, Master Scientist \\ RAI Services Company \\ 401 N Main Street \\ Winston-Salem, NC 27101, USA \\ E-mail:bodnarj@rjrt.com
}

